Marquette University

e-Publications@Marquette

College of Nursing Faculty Research and

Publications

Nursing, College of

$9-2000$

\title{
Influence of Stress and Nursing Leadership on Job Satisfaction of Pediatric Intensive Care Unit Nurses
}

\author{
Marilyn Meyer Bratt \\ Marquette University, marilyn.bratt@marquette.edu \\ Marion Broome \\ University of Alabama, Birmingham \\ Sheryl Talcott Kelber \\ University of Wisconsin - Milwaukee \\ Lynne Lostocco \\ National Association of Children's Hospitals and Related Institutions
}

Follow this and additional works at: https://epublications.marquette.edu/nursing_fac

Part of the Nursing Commons

\section{Recommended Citation}

Bratt, Marilyn Meyer; Broome, Marion; Kelber, Sheryl Talcott; and Lostocco, Lynne, "Influence of Stress and Nursing Leadership on Job Satisfaction of Pediatric Intensive Care Unit Nurses" (2000). College of Nursing Faculty Research and Publications. 386.

https://epublications.marquette.edu/nursing_fac/386 


\section{INFLUENCE OF STRESS AND NuRSING LEADERSHIP ON JOB SATISFACTION of Pediatric Intensive Care Unit Nurses}

Marilyn Meyer Bratt, RN, MS, Marion Broome, RN, PhD. Sheryl Kelber, MS, and Lynne Lostocco, RN, MSN. From Marquette University, Milwaukee, Wis (MMB), University of Alabama at Birmingham (MB). University of Wisconsin-Milwaukee (SK), and the National Association of Children's Hospitals and Related Institutions, Alexandria, Va $(L L)$.

- BACKGROUND High levels of stress and the challenges of meeting the complex needs of critically ill children and their families can threaten job satisfaction and cause turnover in nurses.

- OBJECTIVE To explore the influences of nurses' attributes, unit characteristics, and elements of the work environment on the job satisfaction of nurses in pediatric critical care units and to determine stressors that are unique to nurses working in pediatric critical care.

- METHOD A cross-sectional survey design was used. The sample consisted of 1973 staff nurses in pediatric critical care units in 65 institutions in the United States and Canada. The following variables were measured: nurses' perceptions of group cohesion, job stress, nurse-physician collaboration, nursing leadership, professional job satisfaction, and organizational work satisfaction.

- RESULTS Significant associations $(\mathrm{r}=-0.37$ to $\mathrm{r}=-0.56)$ were found between job stress and group cohesion, professional job satisfaction, nurse-physician collaboration, nursing leadership behaviors, and organizational work satisfaction. Organizational work satisfaction was positively correlated $(\mathbf{r}=$ 0.35 to $\mathrm{r}=0.56$ ) with group cohesion, professional job satisfaction, nurse-physician collaboration, and nursing leadership hehaviors. Job stress, group cohesion, job satisfaction, nurse-physician collaboration, and nursing leadership behaviors explained $52 \%$ of the variance in organizational work satisfaction. Dealing with patients' families was the most frequently cited job stressor.

- CONCLUSIONS Job stress and nursing leadership are the most influential variables in the explanation of job satisfaction. Retention efforts targeted toward management strategies that empower staff to provide quality care along with focal interventions related to the diminishment of stress caused by nurse-family interactions are warranted. (American Journal of Critical Care. 2000;9:307-317)

$\mathrm{N}$ urses working in pediatric intensive care units (PICUs) are specialists within a specialty. These nurses are faced with complex challenges of not only meeting the needs of sick children but also supporting the needs of the children's familics. In addition, issues related to caring for children

Reprint requests: Innolision Commtnication, ,ol Columbia, Aliso Viejo. CA 92656. Pbone, (800) 899-1712 or (949) 362.2050 (ext 515); fax, (949) 362 . 2049; e-mail. iveReprint@aolcom. who are in pain, suffering, or dying can be extremely stressful. Contributing to the stress that PICU nurses perceive are current trends in healthcare of cost containment, unit downsizing, increased acuity of patients, technological advances, and diminishing resources. All these factors can influence nurses' satisfaction with their jobs.

Leaving the job (turnover) is more likely among nurses who experience stress and lack of satisfaction 
in their jobs than among nurses who do not experience these conditions. Oehler and Davidson' reported that job stress is the strongest predictor of burnout in pediatric nurses. Pediatric nursing attracts a unique group of nurses who are committed to the care of sick children. Because of the self-selection to this specialty, maintaining job satisfaction and retention of these nurses is critical.

Many of the factors that affect nurses' job satisfaction have been linked to elements in the practice environment. Previous research focused on the relationship between nurses' job satisfaction and job stress, ${ }^{1.5}$ management style of the nursing leadership, ${ }^{4,5-8}$ empowerment, ${ }^{9,10}$ group cohesion, ${ }^{3.11}$ nurse-physician collaboration, ${ }^{12.13}$ and quality of care. ${ }^{2}$ The relationship between nurses' job satisfaction and retention, intent to stay, or turnover has also been investigated. ${ }^{23,14 \cdot 19}$ Studies $^{3,7,20.21}$ have also explored the influence of individual characteristics of nurses, such as age, experience, and anticipated turnover. Characteristics of nurses' work setting, particularly type of shift ${ }^{3}$ and shift length, ${ }^{+.22}$ have also been examined in relationship to job satisfaction and levels of job stress.

Meta-analyses ${ }^{23,24}$ of job satisfaction and existing studies consistently emphasize the important relationship between nurses' job satisfaction and the nurses' perceptions of a positive work environment, cohesive and collaborative staff relations, and supportive management. These studies also illustrate the adverse influence that stress has on nurses' satisfaction and the quality of patients' care.

Previous studies examined factors influencing nurses' satisfaction across a variety of acute care inpatient units but largely neglected nurses who work in PICUs. Because of the lack of previous research related to job satisfaction and pediatric nurses, it is unknown whether existing models of job satisfaction are relevant to this specialty. The purpose of this study was to explore factors that influence nurses' job satisfaction, including nurses' attributes, characteristics of the PICU, and nurses' perceptions of the work environment across a multiinstitutional population of PICU nurses. The specific research questions were as follows:

1. What is the relationship between perceptions of the work environment and job satisfaction?

2. What is the relationship between nurses' attributes, perceptions of factors in the work environment, and job satisfaction?

3. What factors best predict nurses' satisfaction with their jobs?

4. What is the relationship between unit characteristics, perceptions of factors in the work environment, and job satisfaction?

5 . What are the unique stressors for nurses working in a PICU?

\section{Conceptual Model}

The model for this study (see Figure) is based on research, ${ }^{2,3,11,18.19,25}$ job satisfaction, and turnover. Variables included in the model are those that were significant in studies of nurses from other specialties. On the basis of more recent information, ${ }^{2,6.10 .26}$ the variable of nursing leadership was added because of its influential role in nurses' job satisfaction. Likewise, researchers are beginning to explore the relationship between nurse-physician collaboration

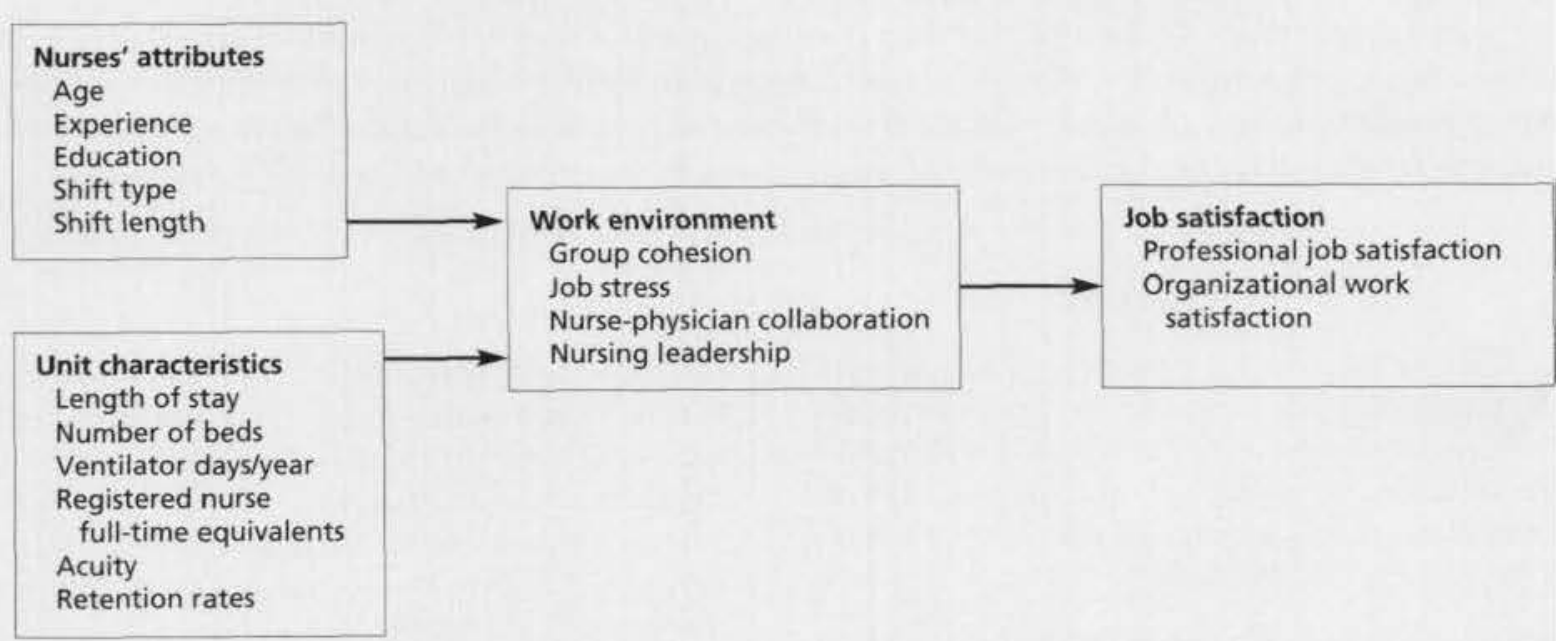

Theoretical model of the relationship among the study variables. 
and job satisfaction. ${ }^{12,12}$ Because of the collegiality that nurses and physicians share in the PICU and the need for collaboration, the effect of this variable on job satisfaction was of interest. Last, because pediatric critical care is a distinct subspecialty, the unique influences of individual nurses' attributes, the characteristics of the PICU, such as the size of the unit and the acuity of the patients, and the role of stress needed to be explored.

\section{Methods}

A cross-sectional descriptive study was used.

\section{Participants}

The sample consisted of 1973 registered nurses. The sample was drawn from 65 pediatric acute care institutions that were members of the National Association of Children's Hospitals and Related Institutions, an association of pediatric facilities in the United States and Canada.

\section{Procedure}

The National Association of Children's Hospitals and Related Institutions coordinated the study across the participating institutions and provided administrative support. The principal investigator (MB) held a joint appointment with a major university and one of the association member hospitals. The project coordinator (LL), employed by the national association, managed the study and maintained communication across institutions. Each participating institution had a designated site coordinator who was responsible for obtaining approval from the appropriate institutional review board and for implementing the study at that site. A doctoral student (MMB) and a university cen+ ter for nursing research provided research assistance, data management, and statistical analysis (SK).

Study instruments werc compiled in a packet of teleformatted questionnaires and were distributed to each institution. The site coordinators, at regularly scheduled nursing staff meetings, recruited participants. Data were collected once at each site during a 3-month period.

\section{Measurements}

The following predictor variables were measured by using self-report questionnaires: job stress, nursing leadership, group cohesion, and nurse-physician (PICU attending physician) collaboration. The outcome variable job satisfaction was considered a multidimensional construet made up of elements essential to enjoyment and fulfillment in a person's job. Two measures of satisfaction were used: a measure related to professional job satisfaction and a measure related to organizational work satisfaction." Professional job satisfaction is a more global measure, whereas organizational work satisfaction is a multifactorial measure composed of elements related to the performance of the job and the larger organization. Table $l$ is a summary of the variable definitions, measures, and psychometric properties. All measures had adequate reliability and validity. ${ }^{2.34 .411 .2 \%-24.3:}$ In addition, demographic information was collected on characteristics of each PICU and on individual nurses* attributes. Last, in order to determine the nature of stressors that PICU nurses experience, an open-ended question asking nurses to state what they thought was "uniquely stressful about working in a pediatric intensive care unit" was included.

\section{Data Analysis}

The data were analyzed by using SPSS 10.0 for Windows (SPSS Inc, Chicago, Ill, 1998). Descriptive statisties were used to deseribe the study sample. 7ero-order correlation analysis was used to examine the relationship between the study variables. Analysis of variance was used to determine differences in work environment vartables and job satisfaction according to nurses' demographic chatacteristics (age groups, amount of ICU experience, education, type and length of shift worked). Regression analysis was used to determine the predictive ability of the work environment variables on job satisfaction.

In order to maximize the sample size with each variable measured, all useable data were analyzed. However, not every participant provided uscable data on each questionnaire; therefore variable sample sizes are noted for the statistical analyses. The largest discrepancy for the differences in sample sizes is for the variable nurse+physician collaboration. Nurses were asked to complete 2 collaboration instruments: an instrument about collaboration with PICU attending physicians and an instrument about collaboration with nonattending physicians. Respondents perceived the 2 instruments as duplicative, and some nurses did not complete both instruments. Because of the large amount of missing data on the collaboration between nurses and nonattending physicians, this variable was deleted from further analyses.

In order to determine the relationship between unit characteristies and the work environment variables, data were aggregated to the unit level. In order to justify the aggregation of individual data to the unit level, criteria

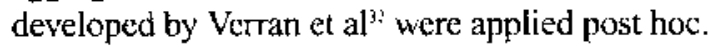

The first eriterion, content validity, was assessed by evaluating each instrument to determine if the 
Table 1 Variables and measures

Variable and definition

Instruments and subscales

No. of items

Cronbach $\alpha$

Group cohesion

General sense of individuals wanting to stay

Group Judgment Scale ${ }^{27}$

6 (7-point Likert)

.85

in a particular group

\section{Job satisfaction}

Multidimensional construct made up of elements essential to the enjoyment or liking of a person's job

\author{
Work Satisfaction Scale ${ }^{\text {"I }}$ \\ (Organizational work satisfaction) \\ Administration \\ Interaction \\ Pay \\ Professional status \\ Task requirements \\ Nursing Job Satisfaction Scale" \\ (Professional job satisfaction) \\ Enjoyment \\ Quality of care \\ Time to do the job \\ Job Stress Scale" \\ Competence \\ Physical work environment \\ Staffing \\ Team respect
}

\section{Job stress}

The amount of stress nurses perceive in relationship to their jobs and work environment

\section{Nurse-physician collaboration \\ Sharing by nurses and physicians of responsibility for problem solving and decision making related to patients' care ${ }^{28}$}

\section{Nursing leadership behaviors}

Management behaviors that enable staff to accomplish their work in meaningful ways

\section{Nurse attributes}

Demographic characteristics of the nursing staff (age, experience, education, shift length and type)

\section{Unit characteristics}

Demographic characteristics (number of beds, length of stay, ventilator days per year, registered nurse full-time equivalents, acuity, retention rate, number of intensivists)

NA indicates not applicable.
Collaboration and Satisfaction About Care Decision ${ }^{28}$
Leader Empowering Behaviors ${ }^{29.30}$ Enhancing meaningfulness of work
Fostering participation in decision making
Facilitating goal achievement Expressing confidence in high performance
Providing autonomy from
bureaucratic constraints

Demographic Questionnaire

Nurse Manager Unit Demographic Questionnaire
15

NA

$\begin{array}{ll}32 \text { (5-point Likert) } & \begin{array}{l}.83 \\ \text { Subscales, } \\ .60-.84\end{array} \\ & \\ 23 \text { (5-point Likert) } & .86 \\ & \begin{array}{l}\text { Subscales, } \\ .62-.78\end{array} \\ & \\ 22 \text { (4-point Likert) } & .85 \\ 8 \text { (7-point Likert) } & \text { Subscales, } \\ .65-.82 \\ \end{array}$

27 (7-point Likert) $\quad .96$

Subscales, $.67-.95$

24

NA items reflected perceptions of the work group or the unit rather than the perceptions of individual nurses. Verran et al $^{32}$ suggest that $90 \%$ of the items should reflect the collective referent group. According to an analysis, 3 of the instruments met this criterion: those on nursing leadership behaviors, collaboration, and group cohesion. However, 3 other instruments did not meet this criterion. Approximately $45 \%$ of the items on the job stress instrument and $72 \%$ of the items on the organizational work satisfaction scale referred to the group or the unit, and $100 \%$ of the items on the nursing job satisfaction scale referred to the individual nurse. Because of the influential nature of the work group or the unit on nurses' perceptions of stress and 
job satisfaction, it was concluded that aggregation of individual responses reflected the collective unit's impressions, thereby allowing analysis at the unit level. ${ }^{2}$

Representativeness, the second criterion, is determined by ensuring that the majority of the members of the group respond. In this study, the response rate was $70 \%$, a percentage that exceeds the recommendation by Verran et al that at least a $50 \%$ response rate is acceptable for group representation.

The last criteria for aggregation to the unit level are reliability and validity. Reliability was assessed by calculating the Cronbach $\alpha$ for the item means of the aggregated data. The Cronbach $\alpha$ for each instrument was acceptable, ranging from .83 to .96 (Table 1). Comparison of variability within the group with variability across the group to assess intraclass correlation was not performed to determine validity.

Major themes of qualitative data on stressors in the PICU were determined by using content analysis. Data were then clustered into the thematic categories that emerged. In some instances, specific quotes that illustrated a particular theme were included in the results.

\section{Results}

The return rate on the questionnaires was $70 \%$.

\section{Characteristics of the Sample}

At the time of the study, all the subjects had been employed in pediatric critical care for a minimum of 3 months and worked at least 20 hours per week $(0.5$ full-time equivalents [FTEs]). The majority of the sample were staff nurses $(86 \%)$ with baccalaureate or higher degrees in nursing $(61 \%)$. More than half $(58 \%)$ of the respondents were less than 36 years old; $90 \%$ were less than 46 years old. The largest part of the sample had 6 to 10 years of experience in intensive care $(28 \%)$ and 6 to 10 years of tenure at the current institution $(27.7 \%)$. New graduates accounted for only $3.6 \%$ of the sample, and more than a quarter $(27 \%)$ of the respondents had been in their current position less than
2 years. Nurses were almost evenly divided between the type of shift worked, with $34.7 \%$ working days, $31.3 \%$ working nights, and $31.2 \%$ working rotating shifts. The mean number of hours worked per week was $36(\mathrm{SD}=9.18) ; 72.4 \%$ of the sample worked 12 hour shifts, and $12.1 \%$ worked 8 -hour shifts.

\section{Characteristics of the Units Sampled}

A total of 70 units volunteered to participate in the study. These units were located primarily in academicbased institutions ( $46 \%)$ and/or freestanding children's hospitals $(47 \%)$. The units had a mean of 17.81 beds $(\mathrm{SD}=7.03$, range $=6-38)$, a mean length of stay of 4.19 days $(\mathrm{SD}=1.35$, range $=2.1-8.6)$, and a mean daily census of 12.19 patients $(\mathrm{SD}=5.85$, range $=2.4$ $30)$. The mean number of ventilator days per year was 2142 , and the mean number of patient days per year was 4243 . The mean number of registered nurse FTEs per unit was $41.29(\mathrm{SD}=23.31$, range $=4.0-95.3)$.

Each unit's nurse retention rate was determined by calculating the percentage of individual nurses who were retained during the 12 months preceding data collection. According to this calculation, the mean retention rate was $80.46 \%(\mathrm{SD}=14.71 \%$, range $=57 \%-100 \%$ ).

\section{Nurses' Job Satisfaction and \\ Perceptions of the Work Environment}

PICU nurses felt positive about the cohesiveness of their peer group on the unit, were moderately satisfied with their jobs, generally felt empowered by nursing management, and felt satisfied with the degree of collaboration that took place with their physicians. However, nurses reported being stressed in their jobs. The means, SDs, and ranges for the study variables are summarized in Table 2 .

Results of the zero-order correlations revealed that the 2 measures of satisfaction, organizational work satisfaction and professional job satisfaction, were positively correlated with each other $(r=0.46)$

Table 2 Work environment variables: means, SDs, and ranges

\begin{tabular}{lllll} 
Variable & & & & \multicolumn{2}{c}{ Range } \\
\cline { 4 - 5 } & Mean & SD & Potential & Actual \\
Group cohesion $(n=1963)$ & 5.18 & 0.91 & $1.00-7.00$ & $1.17-7.00$ \\
Job stress $(n=1953)$ & 2.05 & 0.39 & $1.00-4.00$ & $1.09-3.33$ \\
Nurse-physician collaboration $(n=1728)$ & 4.34 & 1.38 & $1.00-7.00$ & $1.00-7.00$ \\
Nursing leadership behaviors $(n=1960)$ & 4.04 & 1.08 & $1.00-7.00$ & $1.00-7.00$ \\
Organizational work satisfaction $(n=1973)$ & 3.03 & 0.40 & $1.00-5.00$ & $1.68-4.45$ \\
Professional job satisfaction $(n=1970)$ & 3.35 & 0.44 & $1.00-5.00$ & $1.73-4.74$ \\
\hline
\end{tabular}


Table 3 Correlation matrix for study variables*

\begin{tabular}{|c|c|c|c|c|c|}
\hline Variable & 1 & 2 & 3 & 4 & 5 \\
\hline 1. Group cohesion & & & & & \\
\hline 2. Job stress & -0.43 & & & & \\
\hline $\begin{array}{l}\text { 3. Nurse-physician } \\
\text { collaboration }\end{array}$ & 0.29 & -0.37 & & & \\
\hline $\begin{array}{l}\text { 4. Nursing } \\
\text { leadership } \\
\text { behaviors }\end{array}$ & 0.40 & -0.47 & 0.34 & & \\
\hline $\begin{array}{l}\text { 5. Organizational } \\
\text { work satisfaction }\end{array}$ & 0.52 & -0.56 & 0.35 & 0.56 & \\
\hline $\begin{array}{l}\text { 6. Professional job } \\
\text { satisfaction }\end{array}$ & 0.29 & -0.52 & 0.20 & 0.28 & 0.46 \\
\hline
\end{tabular}

and had significant positive correlations with nursing leadership behaviors, group cohesion, and nursephysician collaboration. On the other hand, job stress had significant negative correlations with all the other variables. Job stress was negatively correlated with organizational work satisfaction $(r=-0.56)$, professional job satisfaction $(r=-0.52)$, nursing leadership behaviors $(r=-0.47)$, group cohesion $(r=-0.43)$, and nurse-physician collaboration $(r=-0.37)$. Table 3 is a summary of the results. All reported correlations were significant at $P<.001$.

\section{Predictors of Job Satisfaction}

With the individual nurse as the level of analysis, stepwise multiple regression was used to determine the contribution of the study variables to organizational work satisfaction. The entire model explained $52 \%$ of the variance in organizational work satisfaction. Job stress alone explained $32 \%$ of the variance; nursing leadership, an additional $11 \%$; group cohesion, $6 \%$; professional job satisfaction, $3 \%$; and nurse-physician collaboration, $0.5 \%$.

Another stepwise multiple regression was done with professional job satisfaction as the dependent variable. The entire model explained $31 \%$ of the variance in professional job satisfaction. Job stress explained $27 \%$ of the variance; organizational work satisfaction, $3 \%$; and nursing leadership, $1 \%$.

\section{Nurses' Attributes, Perceptions of the Work Environment, and Job Satisfaction}

In order to ascertain their influence on perceptions of factors in the work environment, nurses' characteristics were examined. A 1-way analysis of variance was used to determine differences in the study variables according to type of shift worked, number of hours in the shift worked (shift length), age categories, education, and amount of ICU experience.

Shift Type. Four types of shifts were compared: days, nights, evenings, and rotating. Differences between shift types were significant for professional job satisfaction, job stress, nursing leadership behaviors, and nurse-physician collaboration. Post hoc comparisons revealed that nurses who worked day shifts perceived significantly higher levels of collaboration with physicians than did nurses who worked evening and night shifts. Nurses who worked rotating shifts perceived significantly more collaboration than did nurses who worked night shifts. Nurses who worked day shifts perceived significantly higher levels of leadership behaviors than did nurses who worked night shifts. Nurses who worked rotating shifts perceived higher levels of stress than did nurses who worked either day or night shifts. Last, nurses who worked night shifts perceived significantly higher levels of professional job satisfaction than did nurses who worked all other shifts. The results are summarized in Table 4.

Shift Length. Four different shift lengths, 8 hours, 10 hours, 12 hours, and rotating (mixture of 8,10 , and/or 12 hours), were analyzed to determine differences across the study variables. Differences were significant for nurses' perceptions of job stress and professional job satisfaction. Post hoc analysis revealed that nurses who worked mixed shifts had higher levels of perceived job stress $($ mean $=2.19$,

Table 4 Analysis of variance summary table: variable means across type of shift worked

\begin{tabular}{|lcccrrrrr} 
& \multicolumn{9}{c}{ Mean } \\
\cline { 2 - 5 } Variable & Days & Evenings & Nights & Rotating & df & F & $P$ \\
\hline Group cohesion & 5.22 & 5.21 & 5.22 & 5.08 & 3,1638 & 2.46 & .06 \\
Job stress & 2.01 & 2.14 & 2.03 & 2.13 & 3,1632 & 9.42 & .001 \\
Nurse-physician collaboration & 4.52 & 3.95 & 4.08 & 4.31 & 3,1631 & 10.12 & $<.001$ \\
Nursing leadership behaviors & 4.14 & 3.88 & 3.93 & 4.05 & 3,1633 & 3.78 & .01 \\
Organizational work satisfaction & 3.03 & 2.99 & 3.00 & 3.03 & 3,1645 & .63 & .60 \\
Professional job satisfaction & 3.34 & 3.22 & 3.41 & 3.33 & 3,1643 & 5.15 & .002 \\
\hline
\end{tabular}


Table 5 Comparisons of variable means between nurses with various lengths of experience in an intensive care unit Mean length of experience, years

\begin{tabular}{|c|c|c|c|c|c|c|}
\hline Variable & $<2$ & 2-5 & $>5$ & $d f$ & $F$ & $p$ \\
\hline Group cohesion & 5.29 & 5.22 & 5.14 & 2, 1915 & 3.20 & .02 \\
\hline Job stress & 2.17 & 2.10 & 1.99 & 2,1918 & 31.42 & $<.001$ \\
\hline Nurse-physician collaboration & 4.46 & 4.20 & 4.37 & 2. 1924 & 4.16 & .02 \\
\hline Nursing leadership behaviors & 4.19 & 3.97 & 4.03 & 2,1923 & 4.44 & .01 \\
\hline Organizational work satisfaction & 3.11 & 2.99 & 3.03 & 2, 1917 & 9.8 & $<.001$ \\
\hline Professional job satisfaction & 3.32 & 3.36 & 3.36 & 2,1918 & .88 & 42 \\
\hline
\end{tabular}

range $=1-4)$ than did nurses who worked 10-hour $($ mean $=1.99)$ and 12 -hour shifts $($ mean $=2.04)$ $\left(\mathrm{F}_{3,1607}=6.69, P<.001\right)$. Nurses who worked a mixture of shift lengths also had lower levels of professional job satisfaction $($ mean $=3.24$, range $=1-5)$ than did nurses who worked 12-hour shifts (mean = 3.38) $\left(\mathrm{F}_{3,1601}=5.32, P=.001\right)$.

Level of Education. In order to examine differences in type of education, nurses with associate degrees were grouped with diploma nurses and compared with nurses with baccalaureate and higher degrees. No significant differences were found across any of the study variables according to type of educational background.

Age. Nurses were grouped into 3 age categories, 20 to 30 years $(n=623), 31$ to 40 years $(n=855)$, and 41 years and older $(n=453)$. Differences between the categories were significant only for the amount of perceived job stress. Younger nurses (20-30 years old) experienced significantly more job stress than did the 2 other age groups $\left(\mathrm{F}_{2,1928}=13.72, P<.001\right)$.

ICU Experience. Experience in an ICU was divided into 3 categories: less than 2 years, 2 to 5 years, and more than 5 years. Post hoc comparisons revealed that for all the study variables except professional job satisfaction, differences between nurses with less than 2 years of ICU experience and all other groups of nurses were significant (Table 5). Furthermore, nurses with less than 2 years of experience had the highest means for all the study variables except professional job satisfaction, in which all group means were not significantly different.

\section{Unit Characteristics, Perceptions of the Work Environment, and Job Satisfaction}

In order to determine the relationship between unit characteristics and perceptions of the work environment, data were aggregated to the unit level. No significant relationships were found between any of the study variables. However, it was hypothesized that differences might exist between units according to the acuity level of patients on the units. An "acuity variable" was constructed that was based on a ratio of the number of ventilator days per unit in the preceding year and the number of registered nurse FTEs for that unit. Fifty-two units provided data on both variables. The ratios for the sample were ranked across 4 quartiles. Units in the upper quartile were categorized as high acuity $(n=12)$; those in the lowest quartile, as low acuity $(\mathrm{n}=13)$; and those in the 2 middle quartiles, as moderate acuity $(\mathrm{n}=27)$. A 1 -way analysis of variance was used to compare differences across the 3 groups (Table 6). Significant differences were found across the 3 groups for all the variables except professional job satisfaction. Nurses on units with low acuity had significantly higher means on perceptions of group cohesion, collaboration with physicians, nursing leadership behaviors, and organizational work satisfaction than did nurses on units with moderate or high acuity. On these same units, nurses also perceived significantly lower levels of job stress.

\section{Stressors in the PICU}

A total of 1241 nurses provided qualitative responses to the open-ended question about unique stressors in the PICU. Content analysis of the responses revealed 3 major themes: issues concerning families, staffing, and death and dying. Family issues and dynamics were the most frequently cited stressors, reported by more than half of the respondents. Respondents acknowledged that it was stressful dealing with parents who were strained, difficult, or demanding. Dealing with "parents who are always on the edge," dealing with families in crisis, answering questions, and being held to a higher level of accountability ("having responsibility for someone's child is the greatest stress of all") were stressors reported. Nurses stated that they had " 2 patients, the child and the family" and that both required nursing care. Having parents and family members at the bedside 24 


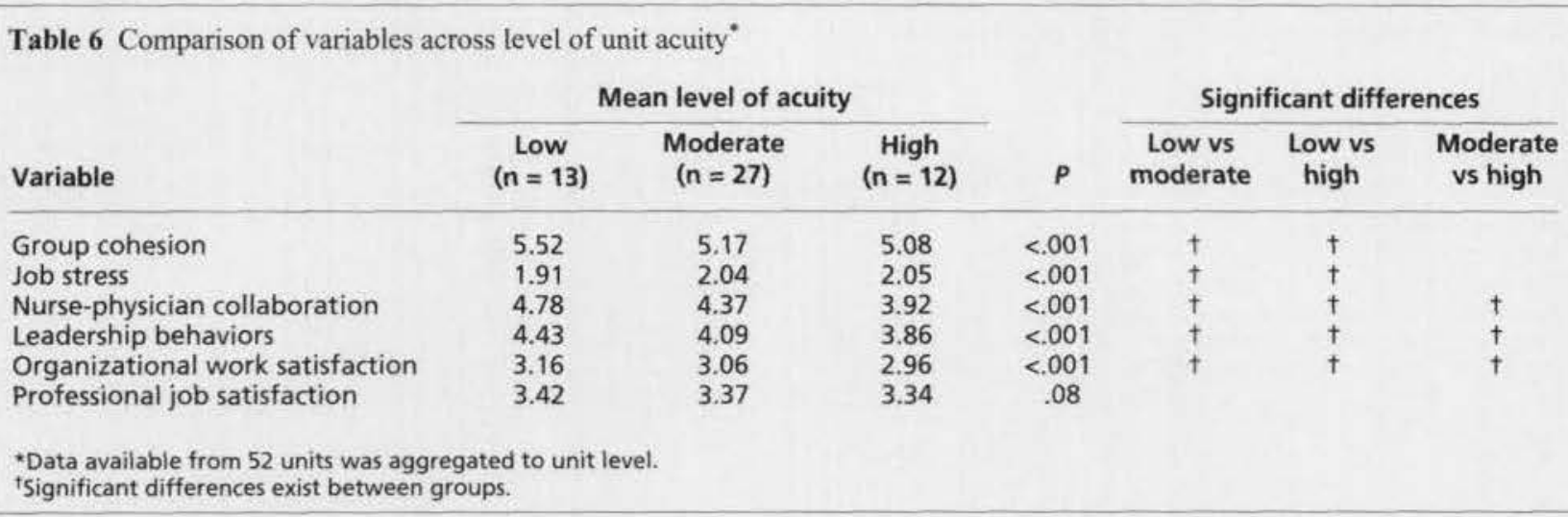

hours per day was another source of difficulty because of the constant intensity of contact and an inability for nurses to get their work done.

Staffing concerns were the next most commonly stated stressor, reported by $27 \%$ of the respondents. Understaffing, high acuity, and unsafe assignments were often cited. Respondents stated that inadequate staffing coupled with high acuity compromised their ability to provide quality care. Heavy workload assignments, failure to take breaks or get meals, inability to attend educational opportunities, inexperienced staff, mandatory overtime, and rapid turnover of patients also contributed to nurses' level of stress.

Children and families who are experiencing dying and death were also prevalent stressors, cited by $22 \%$ of the nurses. Respondents described difficulties witnessing a child's death, experiencing the loss of a child that they have become attached to, and dealing with grieving families. Nurses also reported stress related to the societal norm that children should not suffer and die and to the ethical issues of prolonging a child's life when the outcome is hopeless.

Other stressors reported included the unit environment and working relationships. Difficulties with interpersonal relationships between nurses, shifts, management, and physicians were also described. Other concerns focused on the physical environment, particularly problems of noise, lack of space, and lack of available equipment. Last, nurses described difficulties in dealing with cases of child abuse and the occurrence of preventable injuries such as those experienced by unrestrained children in motor vehicle crashes.

\section{Discussion}

This study was designed to examine factors that influence job satisfaction of nurses who work in PICUs. In general, the respondents scored higher in group cohesion, professional job satisfaction, and organizational work satisfaction and lower in perceived job stress than did nurses in other settings. ${ }^{2.3}$

\section{Job Satisfaction}

Several of the variables explained a significant amount of variance in both professional job satisfaction and organizational work satisfaction. Job stress was the most important predictor of both professional job satisfaction and organizational work satisfaction. Professional job satisfaction reflected how nurses generally felt about their work, whereas organizational work satisfaction reflected their satisfaction with various factors in both the immediate work environment and the larger organization. The relationship between job satisfaction and stress as a major predictor is not surprising because of the small but strong unit culture that is often found in PICUs. High acuity levels, short staffing, and interpersonal relationships are all stressors cited by critical care nurses. ${ }^{5,33.34}$

\section{Nursing Leadership}

The finding that leadership was a strong predictor of work satisfaction corroborate the results of previous research in the area. Leveck and Jones ${ }^{2}$ and Nakata and Saylor' also found that management style was associated with job satisfaction for nurses. Nurses who perceived their managers as having a participative style had higher job satisfaction than did nurses who had a different perception. Similarly, Morrison et al ${ }^{10}$ and Laschinger ${ }^{9}$ found a strong relationship between nurses' job satisfaction and a nursing management style that was perceived as one that empowered staff to perform their jobs effectively. Last, Boyle et $\mathrm{al}^{26}$ also reported a relationship between job satisfaction and managers' characteristics, particularly managers' control over the work environment. 
The results of the study reported here highlight the importance of the nurse-manager relationship and effective leadership as components of job satisfaction for pediatric critical care nurses. The data underscore the notion that nursing leadership that is perceived as supportive, and as providing a cohesive work environment in which nurses can collaborate effectively with other health professionals, has a positive influence on job satisfaction. Nurses want to feel that they are valued members of a team and that their contribution does make a difference, especially in the lives of critically ill children. In today's fast-paced healthcare settings and the stressful PJCU environment, nurses find it crucial to have leaders who remove the barriers and secure for the nurses the resources needed for the provision of quality care.

\section{Job Stress}

Stress levels were highest among new and inexperienced nurses, a finding consistent with the results of other studies. ${ }^{4}$ This finding is not surprising, because new graduates tend to be the least experienced members of the PICU staff, are least comfortable with collaboration, and are still trying to find their "place" on the unit. The findings of this study did not support those of Gowell and Boverie, ${ }^{4}$ who found that stress levels were highest for nurses who worked 10-hour shifts. In the study reported here, it was not the length of the shift but rather the rotation of shifts that influenced job stress. Job stress was highest for nurses who rotated between types of shifts (days, evening, nights) and different lengths of shifts $(8,10$, and 12 hours $)$.

The analysis of the qualitative data on stressors indicates that families and their constant presence are influential factors in nurses' perceptions of the work environment. PICU nurses can feel overwhelmed trying to deal simultancously with the multiple needs of an acutely ill child and the needs of the child's parents. Family-centered care is a core value in most children's hospitals, ${ }^{15}$ yet implementation of this philosophy can place a significant burden on any nurse who is trying to deliver care to a critically ill child while also caring for the child's anxious family members. Units that allow unlimited family visitation and embrace the family care philosophy should be cognizant of the stress that this practice places on staff personnel. Nurses on these units need to have resources in place to help them deal with complex family situations. Additionally, the time and encrgy needed to support patients' families should be recognized and factored into staff nurses' workload. The emotional impact of caring for dying children is also a concern. In order to deal with this stressor, support systems should be available to help nurses cope with issues of death and dying. ${ }^{\text {. }}$

\section{Group Cohesion}

Group cohesion is most strongly linked to perceptions of the work environment and was a significant predictor of organizational work satisfaction in other studies. ${ }^{2.3}$ ln this study, nurses' perceptions of cohesiveness within the work group did not vary significantly across shift type or shift length. However, perceptions of group cohesion were lowest among nurses who rotated between day, evening, and night shifts. Apparently, cohesiveness, which is a relationship-based variable, is casier to achieve when a person works with the same people on a consistent basis. Perceptions of cohesiveness were also inversely related to level of experience. As nurses gained experience, their sense of cohesiveness declined. On the basis of this finding, retention efforts for more experienced staff should focus on team building and on maintaining a sense of connectedness with the peer work group.

\section{Nurse-Physician Collaboration}

The results provided only modest support for the inclusion of nurse-physician collaboration as a significant variable. Consistent with the findings of Baggs et $\mathrm{al}^{13}$ and Stichler, ${ }^{17}$ nurses ' perceptions of collaboration with physicians, although important, were not strong predictors of job satisfaction. However. Stichler, using an instrument that measured interpersonal aspects of collaboration, found that nursephysician collaboration was a slightly stronger predictor of organizational job satisfaction. Similar to Stichler's findings, the results of the study reported here indicated that nurses who worked evenings and nights had significantly lower perceptions of collaboration than did nurses who worked days. This finding is consistent with the decreased frequency of nursephysician interaction that takes place during the evening and night hours. Inexperienced nurses also perceived higher lcvels of collaboration than did nurses with more experience. This finding most likely is related to a greater need to collaborate as the nurses learn and gain expertise in their new position.

\section{Nurses' Attributes}

The results of this study did not support those of other studies ${ }^{23,24}$ that found an inverse relationship between level of education and job satisfaction. In this study, none of the study variables differed according to level of education. Furthermore, this study did 
not support findings ${ }^{7+4}$ that perceptions of job satisfaction werc greater among older nurses than among younger nurses. In this study, differences in both organizational work satisfaction and professional job satisfaction aeross age groups were not significant.

In a comparison between the varjables and amount of PICU experience, nurses with less than 2 years of experience had the highest means for all the study variables. On the basis of this finding, efforts should be made to maintain these positive perceptions of the work environment as nurses gain tenure on a unit. However, this group of nurses also had the highest levels of job stress. Assisting new staff members in a successful transition into their critical care nursing role is essential to maintaining positive perceptions of the work environment.

\section{Unit Characteristics}

In an effort to capture some indicator of unil acuity, number of ventilator days and number of registered nurse FTEs were combined. Analysis based on the creation of this variable revealed a relationship between acuity and most of the study variables. Units with the lowest acuity had the lowest means for job stress and the highest means for group cohesion, nurse-physician collaboration, nursing leadership behaviors, and organizational work satisfaction. $\Lambda$ s acuity increased the means for job satisfaction and the work environment variables decreased and job stress increased. Interestingly, professional job satisfaction did not vary significantly between units with different levels of acuity. This finding presents a difficult challenge for units with a sicker, mote complex population of paticnts. Linits with large numbers of staff taking care of more acutely ill patients can threaten nurses' satisfaction. Retention efforts in these units should focus on helping nurses deal with the stressors and workload issues associated with caring for the more acutely ill population.

\section{Linit Retention Rates}

In this study, the unit retention rates were originally to be considered as an outcome variable as in other studies. ${ }^{3.1 .1 \times 1.2}$ However, the results did not indicate significant relationships between any of the variables and unit retention rates. The use of retention rates required aggregation of data to the unit level, a step that yielded nonsignificant results for any of the study variables as a predictor of retention. The absence of significant predictors for retention may be due to the lack of variability in retention rates across units rather than to a lack of a relationship between factors.
In order to indirectly assess the influence of the variables on turnover, a more practical alternative would be to examine nurse lurnover as measured by the intent of leaving, or anticipated turnover, which is a person's perception of the possibility of leaving an organization. In other studies, 2.1 .18 .4 anticipated turnover, which is a behavioral intention, was correlated with actual. unit turnover rates.

\section{Limitations and Future Directions}

The cross-sectional design of the study limits the generalizability of the findings. A cross-sectional design, with a single period of data collection, provides only a view of participants" responses at that time. Whether the responses reffect perceptions over a longer period is unknown. Demographic information about sex was nol collected. Possibly, male and female nurses would have different perceptions.

Because of the pivotal role of stress in job satisfaction, research efforts should focus on testing interventions targeted to areas of most concern to PICU nurses, namely family concerns and care of dying children, and to larger organizational issues related to staffing and workload. Nursing management remains a key variable in the job satisfaction of PICU nurses. Research efforts should continue to explore management interventions that empower staff and create a positive work climate.

Future study of the predictive ability of study variables that uses theoretical and statistical modeling techniques is warranted. This study provides important baseline data for future research focused on retention strategies and measures to improve job satisfaction.

\section{ACKNOWLEOGMENIS}

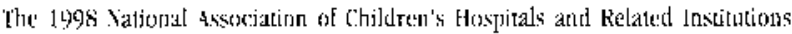
Pediatric Intersive fare linit Focustiroup consisted of the following institutions: Babies and chideren's Ilospital. Sew York, Mi: C.S. Motl children s Hospital-Lnisersity of Michigas Health Sistem. Asta Arbor. Hirh: Childrests

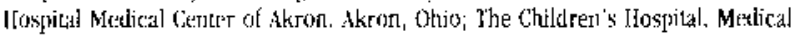
I'nisersity of South Cidroliua, Charlestur, SC: Childrest's Hospital of Alabatua, Birminghim, da: Childrer's Hospital of Michigun. Detroit, Mich; Children's I ospital - [risersity Headeh Sisterns of Eastern Forth Carolina, Greenvilte: VC:

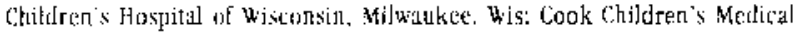

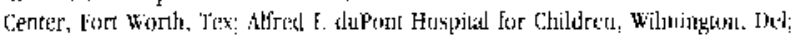
Ituphes Spaulding Children's IJospital, Atlanta. Gid LeBonheur Children's Medical Center, Memphis, Teann: Toma Linda Lrjizersiły children's Hospital, Loma Linda. Calif; Marband's Hespical for Childrer. Baltimore: Md: Stollery Children's Hfealth

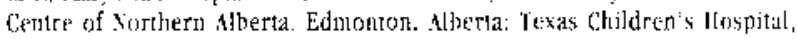

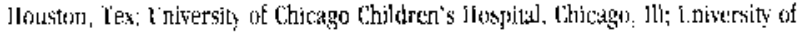
Wiscotisin Children's Hospital, Madism, wis; Fanderloile Children's Jospital: vistrijille. Tenn.

This study was funded be the Nationed Association of childrexts Hospitals and Related lastifutuns.

\footnotetext{
REFRREACES

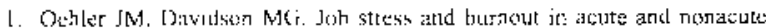

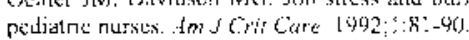

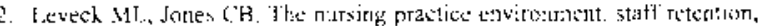




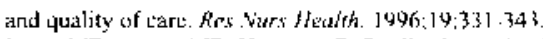

3. Lucas MD, Atwood JR. Hagaman R. Replication and ralidation of anticipat-

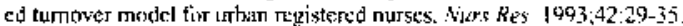

4. Gowell YM, Hoverie PE. Stress and satisfaction as at result of shatt and number of hours worked. Fiters Admin Q. Sumuter 1919:;6:14-19.

5. Sawalrky JV. Stress on crotical care: aclual and perceived. Hedar Lung $1996: 25: 4(19)-4] 7$.

6. Moss R, Rowles CJ. Stafl' nurse job satistaction and management style. Surs Afonage. January 1997;28:32-34.

7. Nakata JA. Saylor C. Mamagernerl style and staff nurse satisfuction in a changing environment. Nurs Admin $Q$. Spring 1994:18:51-57.

8 Volk M(. L Leas $\mathrm{H}$ (), Relationship of management style and anticipated turnover. Dine'ns Crir Care Nurs. 1991.10.35-40.

9. Lasthonger JKS. Impact of leadership behavioss on slaff nurse work ernjowerment. Paper presented at: Meting of the Midwest Nursirg Research Socicty, March 30. 1998; C'olumbus, Ohio.

10. Momisor RS, Jones 1. livilter B. T'te relatjonship between leadershop style and emapowerment of job satisfaction of nurses. J Neers Admin. May $1997: 27: 27-34$

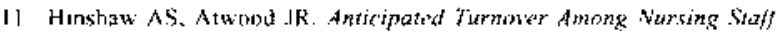
Situd: Final Report. Btethesda. Md: Niational Institutes of Hetalth, National Center for Nursing Research; 1985. Publication R01NL00908.

12. Baggs JG. Schmit MH. Collaboratoon between nurses and physictanx. inage f virs ich. 1988;20:145.144.

13. Baggs JG, Schmitt MII Mushlin AJ, Elaredge DH, Oakes D. Hutsen AD. Nurse-physician collaboration and satisfacling with the decision-malking; process it three critical care urits. An $f$ Crir Cure. 1997:6:393-399

14. Aglıo AO. The moderating effects of dispositional affectivity on relation-

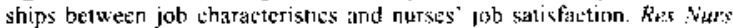
Heath 1993:16:451-458.

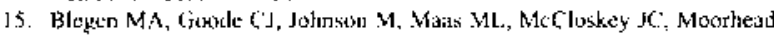
SA. Recognizing staff nurse job perfornance and achicvements. Res . Yiss Hetth. 1092:15:57-66.

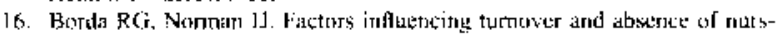
es: a fesearch rer jew. IA $J$ Nors Stud. 1997;34:385-344.

17. Kosmoski KA. Calkın ID). ('ritical cate nutwes" intent to stay in their positwons. Re:s Vurs Heath. $1986 ;-3-10$.

18. Parasuraman S. Nursing tumnever: an intezrated model. Rer Nirs Holth. 1989:12:267-377.

19. Price II. Mueller (w. Professiond Turnoter: The case of tisuses. Janniticu, $N Y$ : Specirutn Publications: 1981 .

20). Alexapder JA, lichtenstein $R$, Oh HJ. Ullman E. A causal model of voluntary turnover among nursing personnel in long-tem psychlatric sctling̨. Res Nums Heatth. 1948:21:415 427.
2. Davidson J. Folearelli FH, Cravilord S, Deprat [.J. ('ilitard JC. The effects of hesilth carc reforms on job satisfaction atd rolututy turnover among hospitid based nurses. Med (are 1997;35:634-645.

22. Bernreuter M, Sullivan M. Survey and critique ol studies relatod to shilt length

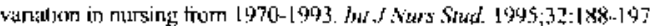

23. Blegen MA. Nurses" job salislaction: a meta-analysis of related variubles. Viurs Res 1998:42:36-40.

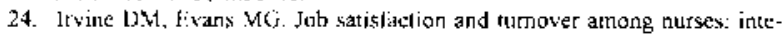
grating research findings across studies. Nurs Res. 1995;44:246-753

25. Hinshaw AS. Arwood JR. Nursing staif turnoter, stress, dind katisfactıon: models, measures and management. Anu Rer Nurs Res. 1983:1:133-153.

26. Boyle DK, Bott MJ, Harıserı HF: Woods CO. Tauntorn RL. Manazers' leadership and critical care uurses" intent to stay. Am $f$ Cril Carc. 1999:8:361-371.

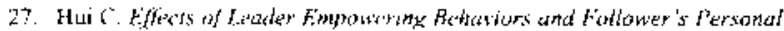
Control, Vuice, and Sedf efficuct an in. Rote and Fxrra-Role Pertormance. A t Fxtension and Fmpirical $T_{\text {ext }}$ of Conger and Kanungo is

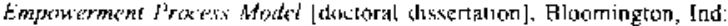
Indiana University; 1994.

28. Conger $\mathrm{IA}$, Kanungo RN. Training charismatic leadership. a lisky and critical lask. In: Cometer IA, Kanungso R.N, eds. Charismatic Leadership:

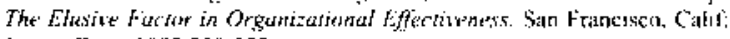
Jossey-[3ass; ] $988: 309-323$

24. Cioud I.R, Nelson [] A. Fiftects of pwerson-group and intragroup attitude similarity on perceited group attriditirness and cohesiveness. Psychol Rep. 1973:33:551+560.

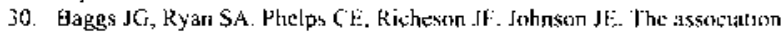
between interdisciplinary collaboration and pacient outcomes in mectical intensive eare. Hean lang. 1947:21:18-24.

31. Bagess $J G_{\text {. }}$. Dewelopment of an instrument to measurs: collaboration and satistaction about care decisions. J thd Nurs. $19144: 20: 1$ ?6. 182 .

32. Verran JA Gertier RM. Milton DA. [Nata aggregation: criteria for psycho-

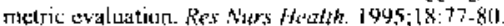

33. Rosenthal SL, Schirnid KD, Black MM. Stress and coping in ad NitCU. Re's Niers Heath 1989;1 2:257-26.5.

34. [opf M. l'etsonality hardiness, accupational stress, and burnout in eritical

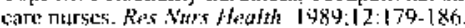

3.. Ahmarn E. Fanily-cetrtered care. [a: \$3roume Ml:, Rollins JA, eds. Corc Curriculum for the trosing Cares of Children and The't Fantilies. Pitman. VJ: Jannetti Publications lnc: I999:373.392.

36. Miles $M$, Demi $A$. Guile in bereaved parents. In: Rando $T$. ed. Purentut Lass of a Chidt (tampaisn. Ill: Research Press; 1986:97-118.

37. Stichler JF. The fiffects of Collatoration. Ulzanizatronat Climate, and

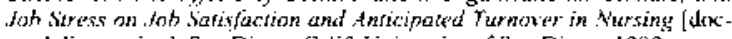
toral dissertation!. San Diego. Calif: Lniversity of San Dicgo; 1990. 